\title{
DYSPLASIA EPIPHYSIALIS PUNCTATA
}

\author{
Report of a Case and Review of Literature
}

\author{
W. W. Frank and M. B. Denny, Durban, South Africa \\ From the Department of Radiology, King Edward VIII Hospital, Durban
}

Punctate epiphysial dysplasia is a rare congenital disorder of infancy affecting mainly cartilage, the soft tissues of the locomotor system such as muscle and joint capsule, and the eyes. Most text-books make no mention of the disorder and few reports have appeared in the literature. Fairbank (1927) was able to find only sixteen case reports, Savignac (1952) only twenty-two, and Putschar (1951) thirty-five. Few had been examined histologically: The rarity of the condition and the histological study have prompted publication of this case.

Conradi (1914) published the first clinical, histological and radiological description of this disease which he called " chondrodystrophia foetalis hypoplastica," which is considered by other writers to be an example of punctate epiphysial dysplasia. Fairbank's first two cases (1927) were described under the title of "epiphysial dysplasia puncticularis"; the name punctate epiphysial dysplasia was suggested by Weber (1936). The names are perhaps misleading, as indicating only skeletal affection, whereas the soft tissues and the eyes are also involved. Many other names have been used in American and Continental literature, the commonest being "chondrodystrophia calcificans congenita." Other synonyms are " chondroangiopathia seu punctata," "stippled epiphyses," and "hypoplastic foetal chondrodystrophy."

The cases described were in infants only, and most of these died in the first few years of life. Fairbank (1951) was unable to find any later report of a case showing generalised changes. Mosekilde (1952) mentioned cases in which the development had been followed over a number of years, but no report is available of a patient living to adult life. Nevertheless Haynes and Wagner (1951) stated that the stippling does heal. In the early phase of healing it is said to resemble aseptic necrosis and the completely healed phase shows linear striae from epiphysial plate into metaphysis.

Etiology and pathology are obscure. Mosekilde (1952) suggested a disturbance of calcium metabolism in mother and child. According to Cocchi (1950) there is a disturbance of blood supply to the epiphyses, especially in the arrangement of the vessels, and the cartilage columns lose their parallel pattern. This observation caused him to suggest the name " chondroangiopathia" as descriptive of the abnormal blood vessels of the cartilage columns seen on histological examination. Harris (quoted by Fairbank 1951) found, as in achondroplasia, patchy mucoid degeneration and cystic spaces in the cartilaginous epiphyses. This observation appears to be confirmed by the histological study of the present case. Haynes and Wagner (1951) reported a case in a sibling of a previously stillborn achondroplasic. The disease is not hereditary but is possibly familial (Maitland 1939, Haynes and Wagner 1951).

The clinical picture is variable but certain signs are common to most of the patients described. These are: 1) flexion deformities of joints, most commonly the knees and elbows, ascribed to fibrosis of muscle and joint capsule rather than to changes in the epiphyses; changes in the soft-tissue structures give the limbs a swollen appearance; 2) bilateral congenital cataract; and 3) dwarfism of the short-limb type, as in achondroplasia. This was well illustrated in the present patient, diagnosed in utero as a foetal achondroplasiac. The parts most affected are the femora and humeri. The shortening is not necessarily symmetrically equal and a single limb may be affected. 
The condition must be distinguished from other diseases presenting mottled, irregula: epiphyses-namely, cretinism and dysplasia epiphysialis multiplex.

\section{CASE REPORT}

A Bantu woman in her fifth pregnancy was referred from the ante-natal clinic of th. King Edward VIII Hospital, Durban, for radiography on account of hydramnios whicl: rendered palpation of the abdomen difficult. Her previous obstetric history was normal. The fourth child, apparently quite well at birth, had died after a week, from unknown cause. - tute-natal radiographs disclosed a foetal abnormality resembling achondroplasia (Fig. 1 . The stippling of the epiphyses could be seen at this stage, through the hydramnios. Three and a half weeks later, at full term, the patient was delivered of a stillborn infant (Fig. : The most striking feature of the foetus was the deformity of the limbs, which were short.

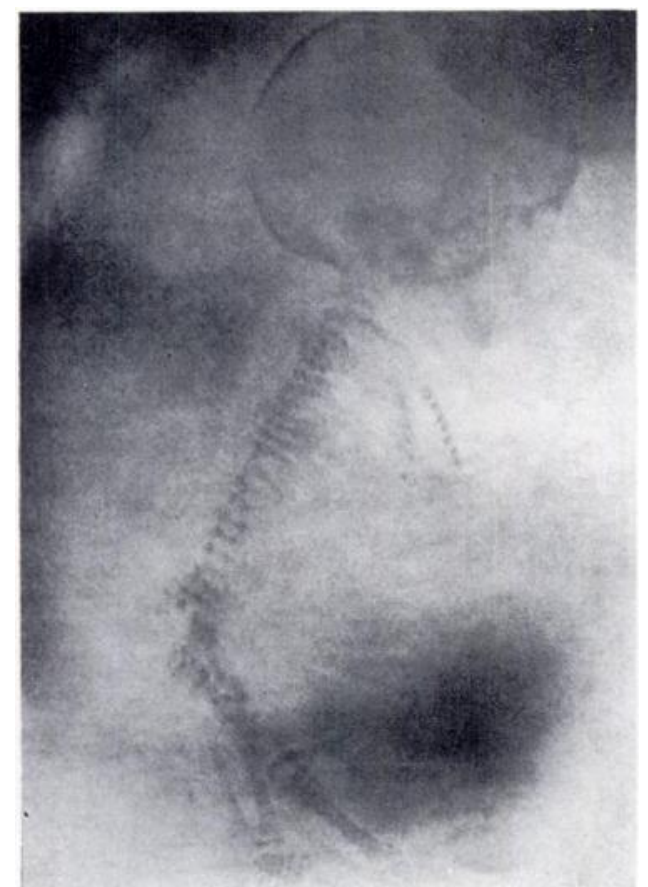

FIG. 1

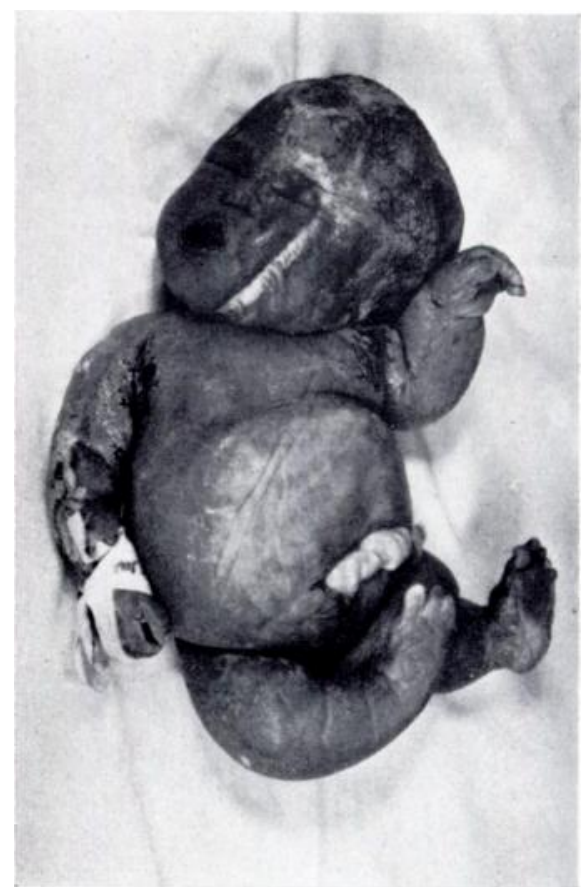

FIG. 2

Figure 1-Ante-natal radiograph showing short limbs and faint stippling. Achondroplasia was suspected. Figure 2-The stillborn foetus showing the short limbs, contractures and the opened mouth presumably due to subcutaneous thickening.

thickened and stubby, especially the left thigh and arm and the left foot. There were well marked flexion deformities of the right knee and left elbow and ulnar deviation at the left wrist. The skull was apparently normal but the mouth was gaping.

Post-natal radiographs were very striking. The sacrum, lumbar and lower thoracic vertebrae consisted almost entirely of opaque dots about a millimetre in diameter, mostly discrete but in places coalescing (Fig. 3). The pelvic bones showed the same stippling, especially in the pubic rami and acetabulum. The alae of the iliac bones were well ossified but the epiphysis of the iliac crests, which normally do not appear until thirteen to fifteen years, were present and stippled (Fig. 3). This premature appearance of epiphyses is described as a feature of the disease. Fairbank mentioned that no case examined by him showed stippling in the iliac crests. The femora showed stippling at both proximal and distal epiphyses (Fig. 4). The left femoral diaphysis was shortened, thickened and bowed, and showed a pseudo-fracture. 
The patella and all epiphyses of the tibiae were stippled. The tarsus consisted entirely of calcified spots with little resemblance to the normal anatomy (Fig. 5). The scapulae showed stippling only at the inferior angles but the left glenoid was deformed. All the epiphyses of the arm and forearm were stippled. The left humerus, radius and ulna, like the left femur, had short, thick diaphyses, and the left radius was much bowed (Fig. 6). The sternum consisted almost entirely of this punctate calcification, and the same appearance was seen in some of the costal cartilages. The hyoid bone and cricoid cartilage were entirely stippled. Faint stippling of base of skull appeared to be present.

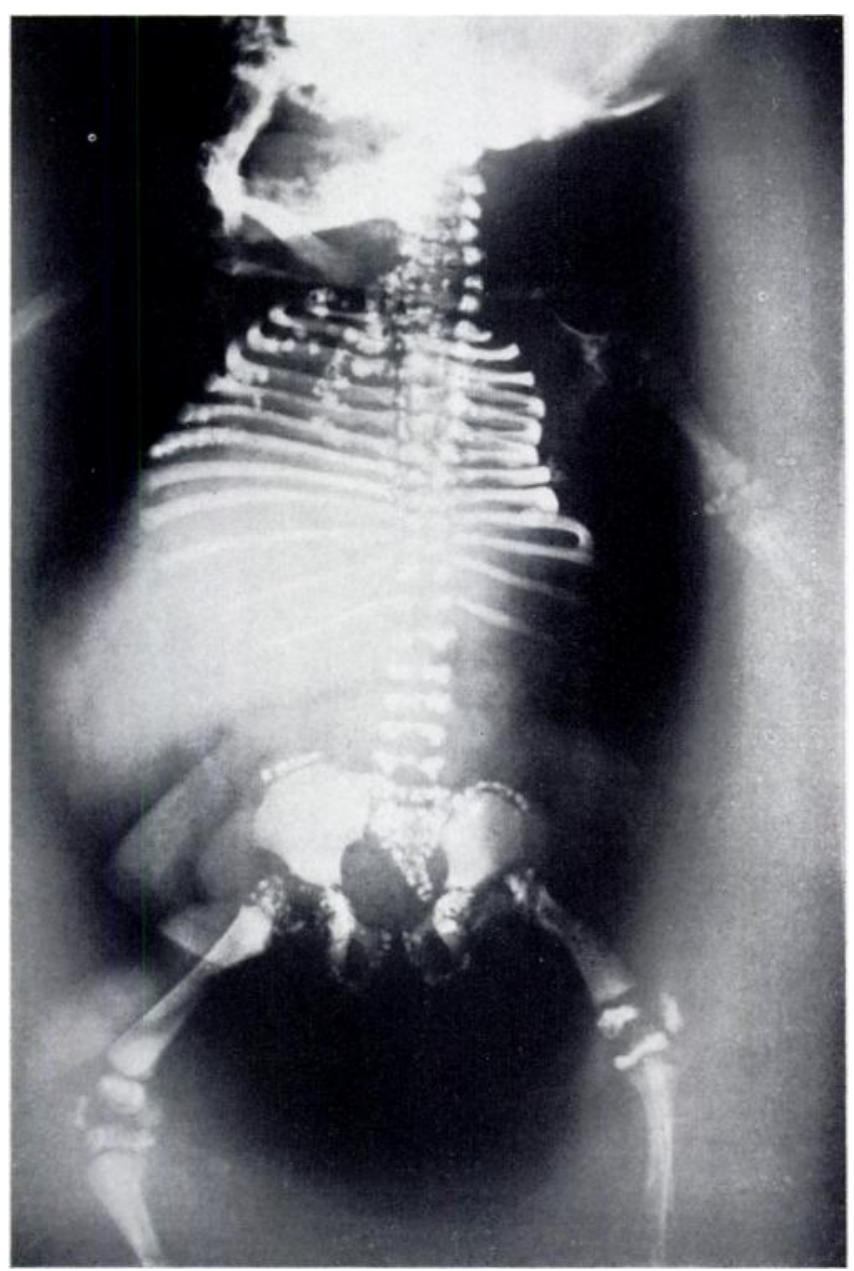

FIG. 3

Radiograph of foetus showing stippling of all epiphyses, the vertebrae and sternum. The base of the skull is sclerotic.

Histological examination (Dr J. Wainwright)-Specimens of bone and cartilage from a femur and costal cartilages were examined. These showed irregular areas of calcification in the cartilage, often surrounded by smaller discrete calcifying foci. In the costal cartilages there appeared to be patchy mucoid degeneration preceding the calcification. Here the cartilage cells had disappeared, and the matrix showed a foamy appearance. Calcified plaques appeared separated by granules of calcified material in the metachromatic-staining stroma. These probably later coalesced near the surface. The calcifying areas were in some places invaded by granulation tissue with osteoclastic cells reabsorbing the calcified material. In the femoral 


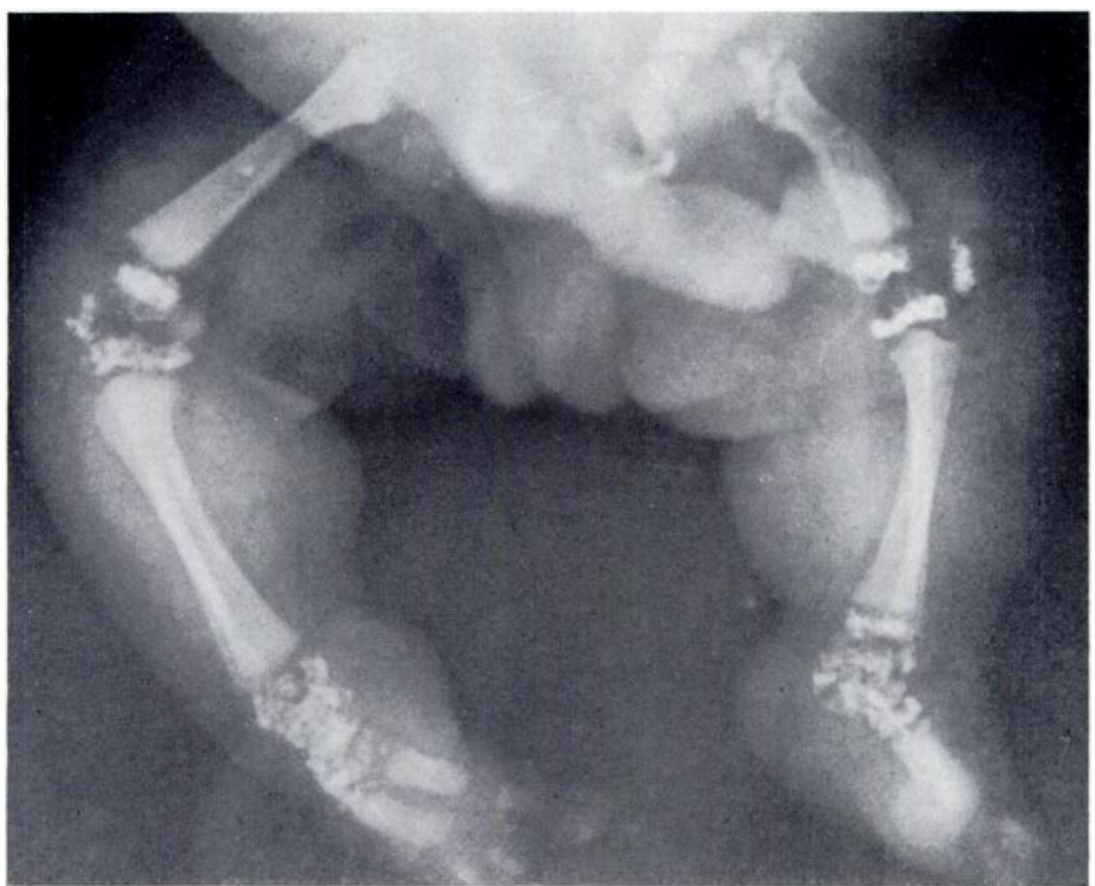

FIG. 4

Lower limbs showing stippling of epiphyses. Note also the marked shortening of the left femur and the pseudo-fracture at its midshaft.

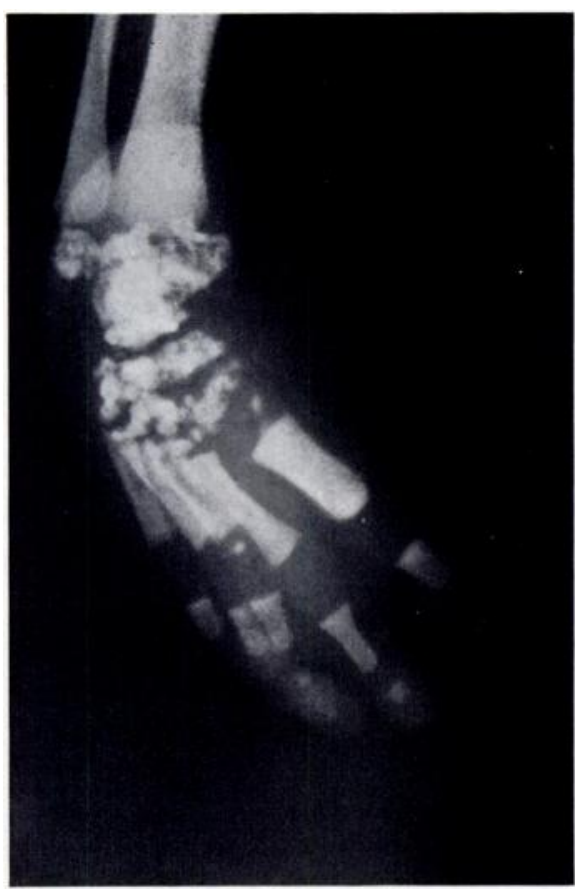

FIG. 5

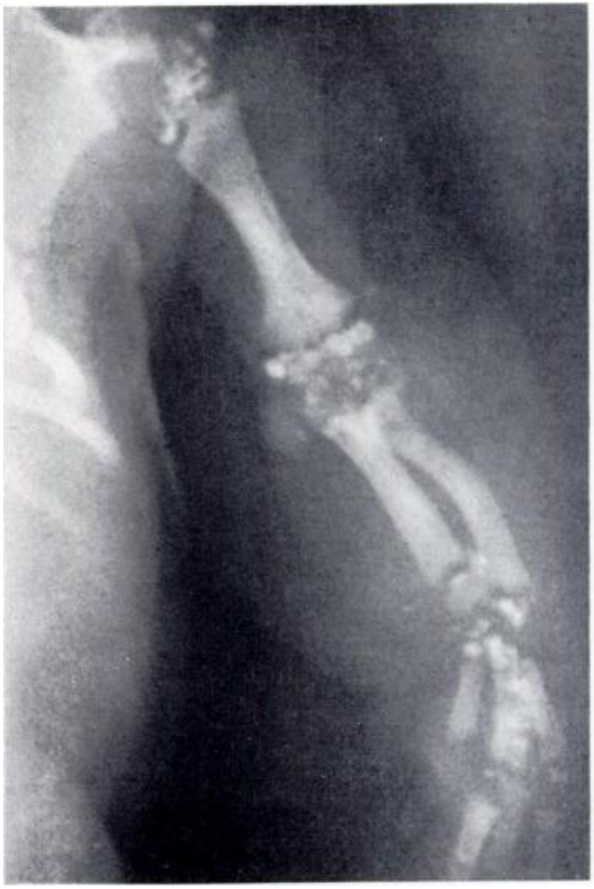

FIG. 6

Figure 5-Right foot showing extensive stippling of the distal tibial and fibula epiphyses and of the tarsal bones. The left foot was similar. Figure 6-Left upper limb showing short diaphyses of humerus, radius and ulna. Note also the bowing of the radius and extensive epiphysial stippling.

VOL. $36 \mathrm{~B}$, NO. 1, FEBRUARY 1954 
epiphysis, however, there were irregular calcified areas in which the cartilage cells were still seen, although their nuclei were undergoing fragmentation (karyorhexis). At the periphery groups of calcified cartilage cells were seen with normal cartilage cells remaining in between. The upper femoral epiphysis appeared normal, but the lower was grossly irregular with failure of orientation of the cartilage cells into columns. Evidence of disordered ossification was also shown by clumps of cartilage in the medullary cavity of the shaft of the femur.

\section{SUMMARY}

Radiological and histological examinations are described in a full term stillborn infant with punctate epiphysial dysplasia diagnosed in utero as achondroplasia.

Thanks are due to Dr J. Parker, Medical Superintendent, and Dr A. L. Gilbey of the Department of Obstetrics, King Edward VIII Hospital, Durban, for permission to publish this case; to Dr J. Wainwright for the histological studies; and to Miss M. McClaggen of the Department of Medical Photography for the photographic reproductions.

\section{REFERENCES}

Bateman, D. (1936): Two Cases, and Specimens from a Third Case, of Punctate Epiphyseal Dysplasia. Proceedings of the Royal Society of Medicine (Section for the Study of Disease in Children), 29, 745.

CocchI, U. (1951): Chondro-angiopathia Calcarea seu Punctata. In Schinz, H. R., et al.: Roentgen Diagnostics, Vol. 1 (Skeleton (Pt. 1), p. 687. Based on the fifth German edition. London: William Heinemann, Medical Books, Limited.

ConRadi, E. (1914): Vorzeitiges Auftreten von Knochen-und eigenartigen Verkalkungskernen bei Chondrodystrophia fötalis hypoplastica. Histologische und Röntgenuntersuchungen. Jahrbuch für Kinderheilkunde, 80, 86.

Fairbank, H. A. T. (1927): Some General Diseases of the Skeleton. British Journal of Surgery, 15, 120.

Fairbank, Sir H. A. T. (1951): An Atlas of General Affections of the Skeleton, p. 102. Edinburgh and London: E. \& S. Livingstone Ltd.

Haynes, E. R., and WAgner, W. F. (1951): Chondroangiopathia Calcarea seu Punctata. Radiology, $57,547$.

Maitland, D. G. (1939): Punctate Epiphyseal Dysplasia Occurring in Two Members of the Same Family. British Journal of Radiology, N.S. 12, 91.

Mosekilde, E. (1952): "Stippled Epiphyses" in the Newborn and in Infants. Acta Radiologica, 37, 291. Putschar, W. G. J. (1951): Chondrodystrophia Calcificans Congenita (Dysplasia Epiphysialis Punctata). Bulletin of the Hospital for Joint Diseases, 12, 514.

Savignac, E. M. (1952): Chondrodystrophia Calcificans Congenita. Radiology, 58, 415.

Weber, F. Parkes (1936): In Discussion of Bateman, D. (1936), p. 747. 